\title{
Demonstrating the non-similarity in local holdups of spouted beds obtained by CT with scale-up methodology based on dimensionless groups
}

\author{
Neven Ali ${ }^{\mathrm{a}}$, Thaar Al-Juwaya ${ }^{\mathrm{a}}$, Muthanna Al-Dahhan ${ }^{\mathrm{ab} *}$ \\ ${ }^{a}$ Nuclear Engineering, \\ ${ }^{\mathrm{b}}$ Chemical and Biochemical Engineering, \\ Missouri University of Science and Technology (Missouri S\&T) - Rolla \\ Rolla, MO 65409
}

\begin{abstract}
The common scale-up methodology for gas-solid spouted bed that has been reported in the literature is based on matching dimensionless groups. This methodology has been validated by measuring global hydrodynamic parameters and non-validated by limited point measurements of solids holdup and velocity. Therefore, the purpose of this work is to implement our advanced non-invasive gamma-ray computed tomography (CT) technique to assess and to demonstrate that the reported set of the dimensionless groups are not adequate in capturing all the interplay phenomena for achieving similarity in local solids and gas holdups cross-sectional distributions and their radial profiles along the bed height measured in 0.076 and $0.152 \mathrm{~m}$ spouted beds. The results clearly identified the three regions (spout, annulus and fountain) of gas-solid spouted beds and their solids structure. In addition, the reported results are valuable as a benchmarking data for CFD and DEM simulations.
\end{abstract}

*Corresponding author:

Tel.: +1 573341 7518; fax: +1 5733414377 .

E-mail addresses: aldahhanm@mst.edu

Keywords Scale-up; Spouted beds; Gamma-ray computed tomography (CT); Cross-sectional distribution; Phase holdup. 


\section{Introduction}

Spouted beds are gas-solid granular contactors suitable to handle heavy, coarse, sticky, and/or irregularly shaped solids through cyclic flow patterns. Gas-solid spouted beds have various industrial applications, particularly physical transformation processes such as coating, drying, and granulation and chemical transformations such as gasification and other reaction processes (Mathur and Epstein, 1974a). These gas-solid contactors have recently been applied in manufacturing TRISO (tristructural-isotropic) nuclear fuel particles for the $4^{\text {th }}$ generation of nuclear energy using chemical vapor deposition (Lee et al., 2008; Liu et al., 2012; Sawa and Ueta, 2004; Tang et al., 2002). The gas-solid interactions in these spouted beds are complex. The gas is introduced through the inlet nozzle at the base of the spouted bed to form a jet that picks the particles up from the annulus and carries them to the top of the bed forming fountain where the falling particles return to the annulus of the bed in a continuous circulation. Hence, three distinct regions, as illustrated in Figure 1, exist in gas-solid spouted beds: the central spout region, the annulus region, and the fountain region. In general, the spouted beds consist of a conical base and a cylindrical column or the whole bed is a conical configuration.

Due to the complex interactions among the phases (gas-solid, solid-solid), the scale-up and design of these contactors/reactors are challenging. Furthermore, most of the studies have focused on measuring the global parameters due to the lack of availability and implementation of advanced noninvasive measurement techniques that can measure local hydrodynamics. Thus, the knowledge and understanding of the interplay hydrodynamics of the spouted beds are limited. Accordingly, the scale-up approaches and methodologies that have been proposed in the literature are based on matching dimensionless groups. He et al. (He et al., 1997) extrapolated the dimensionless groups proposed by (Glicksman, 1984) for gas-solid fluidized beds to scale-up gas-solid spouted beds despite their 
significant differences of the flow patterns of the solids and gas phases. He et al. (He et al., 1997) suggested the following dimensionless groups for scaling up and for the hydrodynamic similarity of gassolid spouted beds:

$\operatorname{gd}_{\mathrm{p}} / \mathrm{U}^{2}, \quad \rho_{\mathrm{s}} \mathrm{d}_{\mathrm{p}} \mathrm{U} / \mu, \quad \rho_{\mathrm{f}} / \rho_{\mathrm{s}}, \quad \mathrm{H} / \mathrm{d}_{\mathrm{p}}, \quad \mathrm{D}_{\mathrm{c}} / \mathrm{d}_{\mathrm{p}}, \quad \phi_{\mathrm{s}}, \quad \varphi, \quad \varepsilon_{\mathrm{o}}$, dimensionless particle size distribution and dimensionless bed geometry.

He et al. (He et al., 1997) added two additional dimensionless parameters which are the internal friction angle $(\varphi)$ and the loose packed bed voidage $\left(\varepsilon_{0}\right)$, to achieve mechanical similarity in the annulus of the spouted bed based on the findings (Sokolovskii, 1965). Since the particles in the spouted beds are always larger than $1.0 \times 10^{-3} \mathrm{~m}$, the non-dimensional coefficient of cohesion, which was also proposed by (Sokolovskii, 1965) for small particles, is neglected (He et al., 1997).

He et al. (He et al., 1997) evaluated experimentally this methodology by using two different sizes of spouted beds at ambient and elevated pressure. They employed conditions where the above dimensionless groups were closely matched and conditions where the dimensionless groups were varied to examine the effect of mismatching of the selected dimensionless groups on the similarity of the hydrodynamics. The spouted beds were operated under all these conditions and at stable spouting. It is noteworthy that (He et al., 1997) used the measurement of the global parameters to validate and assess their proposed methodology. These parameters were maximum spoutable depth $\left(\mathrm{H}_{\mathrm{m}}\right)$, dimensionless maximum spoutable depth $\left(\mathrm{H}_{\mathrm{m}} / \mathrm{D}_{\mathrm{c}}\right)$, dimensionless height $(\mathrm{z} / \mathrm{H})$, dimensionless pressure along the bed height (pressure drop at a certain height/overall pressure drop of the bed where the pressure was measured at the wall), fountain height $\left(\mathrm{H}_{\mathrm{F}}\right)$, and dimensionless fountain height $\left(\mathrm{H}_{\mathrm{F}} / \mathrm{D}_{\mathrm{c}}\right)$. With these measurements, (He et al., 1997) demonstrated the validation of their set of the dimensionless groups mentioned above. In this study, we have overcome the shortcoming of the evaluation by measuring the global parameters. 
Du et al. (Du et al., 2009) modified the scaling of dimensionless groups of (He et al., 1997) by adding the restitution coefficient $\left(\mathrm{e}_{\mathrm{ss}}\right)$ which was estimated experimentally by dropping the particles from a certain height $\left(\mathrm{H}_{\mathrm{o}}\right)$ and measured by high-speed camera the rebounding height $\left(\mathrm{H}_{1}\right)$, where $\mathrm{e}_{\mathrm{ss}}=$ $\left(\mathrm{H}_{\mathrm{o}} / \mathrm{H}_{1}\right)^{1 / 2}$. The suggested parameter was based on the analysis of the kinetic energy of colliding particles in the spout and annulus in spouted beds. They experimentally verified this new set of scaling dimensionless parameters by having spouted beds with matching $\mathrm{e}_{\mathrm{ss}}$ and spouted beds with mismatching $\mathrm{e}_{\mathrm{ss}}$. They used an optical probe to measure voidage profiles, fountain height, and spout diameter and showed that these parameters were closely related to the coefficients of restitution. However, the uncertainty in the measurement of $\mathrm{e}_{\mathrm{ss}}$ has not been quantified. Furthermore, apart from the measurement of the void profiles, the rest of the measured parameters for the assessment are global parameters. In addition, limited measurement points were taken. Also, the optical probe used would introduce some limitations such as disturbance also the probe's tip, size, design and assembly. These limitations were evident through the experimental results of (Du et al., 2009) where an error was observed on the voidage profiles at the middle section of the spouted beds. Their complicated voidage distributions in the middle section of the beds may be attributed to the measurement errors ( $\mathrm{Du}$ et al., 2009). In addition, another disadvantage of their used would be weak light transmission between the tips of the probe when the probe used in dense flow region, which makes this technique ineffective for dense flow system. Since the uncertainty in the estimation of the $\mathrm{e}_{\mathrm{ss}}$ has not been quantified, it has not been considered as in this work as part of the set of the scaling dimensionless groups.

Aradhya (Aradhya, 2013) demonstrated the non-similarity of the solids hold up by limited local point measurements using a new small optical fiber probe when the dimensionless groups proposed by (He et al., 1997) were matched. In spite of the meaningful and valuable efforts of (Aradhya, 2013) to evaluate this methodology, there are still some limitations for in detailed evaluating such method. These 
limitations include invasiveness of the probe, which would affect the local measurements of the solids and gas holdups, and its point measurement nature of the solids holdup and the spout diameter. Unfortunately, there has been no experimental work that used advanced measurement techniques to measure the distribution of the solids, and gas holdups in detail and in a noninvasive manner to assess properly the scale-up methodology that is based on matching dimensionless groups. Accordingly, the purpose of this work is to address for the first time these needs, overcome the above-mentioned limitations, and to demonstrate the non-similarity in local holdups when the set of dimensionless groups of (He et al., 1997) has been matched, by implementing our gamma-ray computed tomography (CT) technique to image the cross-sectional distributions of solids and gas holdups along the bed height and provide the holdups radial profiles.

It is noteworthy that a number of studies implemented computational fluid dynamics (CFD) and the discrete element method (DEM) to simulate various sizes of gas-solid spouted beds. Unfortunately, assessment for validation of these simulations was made using limited measurements of global parameters (Béttega et al., 2009; Du et al., 2006; Duarte et al., 2005; Duarte et al., 2009; Gryczka et al., 2009a; Gryczka et al., 2009b; Hosseini et al., 2013; Lan et al., 2012; Li et al., 2012; Moradi et al., 2013; Ren et al., 2011; Rong and Zhan, 2010; Shuyan et al., 2009; Wang et al., 2006; Wang et al., 2014; Yang et al., 2014; Zhonghua and Mujumdar, 2008). Therefore, our detailed local measurements of the crosssectional distribution and radial profiles of solids and gas holdups will be valuable benchmarking data to evaluate and validate these CFD and DEM simulations. 


\section{Experimental Work}

\subsection{Experimental Set-up of Spouted Beds}

The experimental works were carried out in two spouted bed cylindrical columns with a conical base made of Plexiglas with inner diameters of $0.076 \mathrm{~m}$ and $0.152 \mathrm{~m}$. The schematic diagrams of the two spouted beds are shown in Figure 2. We designed both columns to be geometrically similar with a height of $1.14 \mathrm{~m}$ and a conical base at a 60-degree angle. The two columns were designed without any ports or connections on the wall to eliminate the possibility of any non-symmetric problems that complicate the CT reconstruction process. A high open area gas distributor made of stainless steel was placed at the bottom of the conical base to hold the particles and at the mean time to pass the jet of the gas through the bed. The diameters of the inlet orifice were $9.5 \times 10^{-3} \mathrm{~m}$ for the $0.076 \mathrm{~m}$ spouted bed, and $19.1 \times 10^{-3} \mathrm{~m} \mathrm{for}$ the $0.152 \mathrm{~m}$ spouted bed. The gas used was dry compressed air supplied from an industrial compressor with a capacity of up to $3.47 \times 10^{-1} \mathrm{~m}^{3} / \mathrm{s}$ and $140,600 \mathrm{~kg} / \mathrm{m}^{2}$. The gas flow rate was regulated using a pressure regulator and a rotameters setup that consisted of two rotameters connected in parallel.

It is very important to sustain stable spouting in the spouted bed by satisfying a three criteria or conditions in the operation of the spouted beds. The first criterion was based on the ratio of the inlet orifice diameter to the particle diameter $\left(D_{i} / d_{p}\right)$ which should be smaller than $(<)$ 25 30 (Chandnani and Epstein, 1986)). After (Lim and Grace, 1987) extended the work on a $0.91 \mathrm{~m}$ diameter column, they found it is essential to operate with inlet orifice diameters less than about 30 times the mean particle diameter in order to maintain a stable spouting mode within the spouted bed. The second criterion was based on the ratio of the column diameter for small columns to the inlet orifice diameter $\left(D_{c} / D_{i}\right)$ which should be smaller than $(<)$ 3 12 (Mathur and Epstein, 1974b). The third criterion is that the height of the static bed $(\mathrm{H})$ should be smaller than $(<)$ the maximum height of the spoutable bed (He et al., 1992). 


\subsection{Experimental conditions}

Three different sets of experimental conditions were selected from (He et al., 1997) study which provide matching and mismatching scaling dimensionless groups. This is to evaluate the methodology of achieving hydrodynamics similarity in two different flow fields when the above-mentioned independent dimensionless groups are matched provide that the two flow fields are geometrically similar. The selected experimental conditions include the properties of the particles used and the operating conditions, which are listed in Table 1. Case A was proposed as the reference case. Hence, the conditions of Cases A and B were taken to match as close as possible the dimensionless groups between the two cases to examine the validity of the scaling dimensionless groups. The conditions of Case $\mathrm{C}$ were selected to examine the influence of mismatched scaling groups. The initial bed height $(\mathrm{H})$ and the inner column diameter $\left(D_{c}\right)$ in Case $C$ were $0.16 \mathrm{~m}$ and $0.076 \mathrm{~m}$, respectively, in order to achieve similarity with Case A only on the bed dimensionless groups. The values of scaling groups $H / D_{c}, D_{c} / D_{i}$, and $D_{d} / d_{p}$ of Case $\mathrm{C}$ were equal to those of Case A. However, two important groups of Case C were not matched with those of Case A: Reynolds number and Froude number. The Reynolds numbers for Cases $\mathrm{A}$ and $\mathrm{C}$ were 157 and 54, respectively. The Froude numbers for Cases A and $\mathrm{C}$ were 54.5 and 51.2, respectively. Subsequently, Cases A and B were designated as Cases of matching dimensionless groups, and Cases $\mathrm{A}$ and $\mathrm{C}$ were designated as Case of mismatched dimensionless groups. 


\subsection{Dual Source Gamma Ray Computed Tomography (DSCT)}

Our single and dual gamma-ray computed tomography techniques have been used to visualize various multiphase flow systems (Al-Dahhan, 2009; Al-Dahhan et al., 2007; Bhusarapu et al., 2006; Chen et al., 1999; Kemoun et al., 2001; Kumar et al., 1995; Liu et al., 2011; Luo and Al-Dahhan, 2010; Prasser et al., 2003; Rados et al., 2005; Roy and Al-Dahhan, 2005; Roy et al., 2005; Shaikh and AlDahhan, 2005; Varma et al., 2008). In this work, we used single source (Cs-137) gamma-ray computed tomography, which is part of the dual source gamma-ray computed tomography (DSCT) technique available in our laboratory. For two-phase flow (e.g., gas-solid, liquid-gas, or liquid-solid) systems, only single source is needed to distinguish between the two phases, which is termed here as gamma-ray computed tomography (CT) technique. However, (gas, liquid and solid) the two sources of the DSCT technique are used to determine the phases volume fraction distributions of three phases which are in dynamic movement. Figure 3 shows the DSCT and the related CT techniques. The details of the mechanical assembly, the electronics data acquisition and the setup, and the operation are not presented here but they can be found elsewhere (Varma, 2008).

The source is collimated to have a fan beam shape with a fan angle of $40^{\circ}$. In the opposite of the source, 15 sodium Iodide $(\mathrm{NaI})$ scintillation detectors are arranged in an arc plate. The CT technique can accommodate a column with a diameter up to $0.762 \mathrm{~m}$. The detectors are collimated using a $2.0 \times 10^{-3} \mathrm{~m}$ width and $5.0 \times 10^{-3} \mathrm{~m}$ height slit collimator device attached to each detector. The detectors are 802 Canberra model, consisting of $5.08 \times 10^{-2} \times 5.08 \times 10^{-2}$ meters of cylindrical NaI scintillation crystal, a photomultiplier tube (PMT), an internal magnetic or light shield, aluminum housing, and a 14-pin connector. Each detector is followed by a Canberra preamplifier, which is excited at 900V from a high power supply. The detected signal, from the preamplifier is then amplified using a timing amplifier. The signal is processed and recorded using a multilevel discriminator and a scaler. The detectors arrays are 
used to collect the unattenuated photons of the gamma rays that pass through the multiphase experimental setup. The source and the detectors array are both mounted on a rotational plate that moves them $360^{\circ}$ around the investigated column, offering 197 views in each scan and 21 projections in each view. This rotational plate is connected to another plate that moves axially to selected level position to take the scan along the bed height to produce 2-dimensional and 3-dimensional images. The Cs-137 sealed source (with gamma photon energy of $0.662 \mathrm{MeV}$ ) was used for the spouted bed experiments. The activity of Cs-137 was about $200 \mathrm{mCi}$ at the time of the experiments. The counts for each projection were collected by the collimated detectors for 60 samples at $20 \mathrm{~Hz}$ to collect enough counts and to reduce noise to signal ratio. The means for the data points of each projection, for each sampling method and all scans performed are obtained. The mean value for all the counts based on multiple samples of a given projection is used to process the data.

To acquire the data needed for the CT reconstruction; complete sets of CT scans have been performed in each experiment that aims to obtain the phase holdup distribution. These scans include those when the column is under the desired conditions of the gas-solids spouted bed operation (i.e. the actual test), the column is filled with solids as a packed bed (i.e. spouting gas is absent), and a reference one that is made up when the column is empty (i.e. full of air only). The data obtained from the scans are interpreted in terms of Beer-Lambert's law (equation (1)) and used in the reconstruction process.

$$
I(y)=I_{o}(y) \exp \left[\sum_{x \in X}-h(y \mid x) \mu(x)\right]
$$

The reconstruction domain of the bed was discretized by pixels. Cross-section of a given spouted bed column is encompassed by a square matrix of pixels with dimensions of (n) raws $\mathrm{x}(\mathrm{m})$ columns pixels. The size of the pixels depends on the size of spouted bed column and the achievable spatial resolution of the CT scanner (i.e. the detector collimator width). An even number of pixels is needed on 
each side of the matrix, and hence a suitable number of pixels were selected. The corresponding size of pixels were respectively, $80 \times 80$ and $40 \times 40$ for $0.152 \mathrm{~m}$ and $0.076 \mathrm{~m}$ spouted beds.

For image reconstruction, an alternating minimization (AM) algorithm was applied to reconstruct the efective attenuation coefficient $\hat{\mu}_{s-g}(x)$ in equation (2) for gas-solid spouted beds. The index $x$ in $\hat{\mu}_{s-g}(x)$ refers to each pixel in the image domain. The AM was developed by (O'Sullivan and Benac, 2007) and implemented by (Varma, 2008; Varma et al., 2008) for imaging two-phase systems when a single gamma source is used. The target throughout the AM algorithm is to reformulate the maximumlikelihood estimation problems into the minimum Kullback-Leibler divergence (I-divergence or information divergence) (Csiszár, 1975) and tackle it algorithmically in iterative process. More details and mathematical proofs regarding the AM algorithm are not discussed here but they can be found elsewhere (O'Sullivan and Benac, 2007; Varma et al., 2008).

Algorithmically, the AM is an iterative process, and should start with some initial values in each pixel, and then iteratively adjust them to explore for the effective attenuation coefficient $\hat{\mu}_{s-g}(x)$ values for the pixels. For the pixels outside the spouted bed domain, zero is assigned as shown in Figure 4. With the aid of equation (1) and the AM algorithm, the effective attenuation coefficient is obtained from the transmission ratio $\left(I(y) / I_{o}(y)\right)$ and the known chord length $h(y \mid x)$ for each pixel. Once $\hat{\mu}_{s-g}(x)$ for each pixel is obtained by reconstructing the image from the entire set of projection measurements, the next step is to calculate the phase volume fractions or phase holdups for gas-solid spouted beds as outlined below.

For holdup calculation of a two-phase system, gas-solid spouted bed in this case, $\mu(\mathrm{x})$ in equation (2) below represents the attenuation value, and $\varepsilon$ represents the holdup fraction for each phase. The total 
mass attenuation coefficient in equation (2) equals the sum of the individual phase mass attenuation coefficients weighted by the respective volume fraction. Consequently,

$$
\hat{\mu}_{s-g}(x)=\hat{\mu}_{s}(x) \varepsilon_{s}(x)+\hat{\mu}_{g}(x) \varepsilon_{g}(x)
$$

Where, $x$ is the index of pixel (image coordinate), $\hat{\mu}_{s-g}(x)$ is the effective attenuation value for the gas-solids when the system is dynamic at the desired operating condtion, $\hat{\mu}_{s}(x)$ is the attenuation value for pure solids phase (column contains solids only and spouting gas is absent), $\hat{\mu}_{g}(x)$ is the attenuation value for pure gas phase (empty column), $\varepsilon_{s}(x)$ is the solids phase fraction (or solids holdup), and $\varepsilon_{g}(x)$ is the gas holdup fraction (or gas holdups). Then if we assume $\hat{\mu}_{g}(x)$ is neglected (attenuation for gas is very small at $0.662 \mathrm{MeV}$ ). Hence, equation (2) will become,

$$
\hat{\mu}_{s-g}(x)=\hat{\mu}_{s}(x) \varepsilon_{s}(x)
$$

The sum of the phase holdups is equal to unity $\left(\varepsilon_{\mathrm{s}}+\varepsilon_{\mathrm{g}}=1\right)$. if we replace $\varepsilon_{\mathrm{s}}$ by $1-\varepsilon_{\mathrm{g}}$, the gas holdup becomes equal to

$$
\varepsilon_{g}(x)=\frac{\hat{\mu}_{s}(x)-\hat{\mu}_{s-g}(x)}{\hat{\mu}_{s}(x)}
$$

And the solids holdup is equal to

$$
\varepsilon_{s}(x)=1-\frac{\hat{\mu}_{s}(x)-\hat{\mu}_{s-g}(x)}{\hat{\mu}_{s}(x)}
$$

The $\hat{\mu}_{s}(x)$ value is constant for all pixels in the domain and was obtained using the Beer-Lambert's law after measuring the transmitted energy when the column is filled with solids and the column is empty. The $\hat{\mu}_{s-g}(x)$ values were determined using the AM form scans taken when the column is under the desired conditions of the gas-solids spouted bed operation and the column is empty. Before scans were 
taken, the gas flow rate was introduced into the column, and the bed pressure was set at the desired operating conditions. At least 30 minutes were given for the entire system to allow the flow inside the spouted bed to be stabilized. Once the desired operating condition is achieved, the CT system is employed to take the scan at four vertical locations. For convincing comparisons between the two beds, those vertical locations were non-dimensionalized (i.e. dimensionless heights z/D) as shown in Figure 4. Where $\mathrm{z}$ refers to the actual height from the gas distribution and D refers to the column diameter of the spouted beds. The z/D scan levels for the two beds were; 0.8 at the cone section, 1.1 above the cone section, 1.8, at the middle section and below the bed surface, and 2.4 at the fountain region.

\section{Results and Discussion}

\subsection{The accuracy and reproducibility of the results}

The accuracy of our CT technique results has been confirmed using phantom, which consists of two concentric Plexiglas cylinders where one of them was filled with water. The results have shown the measured linear attenuation of water and the dimensions of the cylinders compared to the actual value were within up to $1 \%$ (Ahmed, 2014; Mesfer, 2013). To ensure the reproducibility of the results obtained using the CT as well as for accurate comparability between the conditions, a repeated set of scans was performed at selected z/D level and the same operation conditions for each case in Table 1. For the sake of brevity, just the reproducibility results for the $0.152 \mathrm{~m}$ spouted bed (Case A in Table 1) are demonstrated here. Figure 5 shows the solids holdup cross-sectional distributions and their radial profiles (solids holdup versus the dimensionless radius $(\mathrm{r} / \mathrm{R})$ ) with the associated error bars for three CT scans at level of $\mathrm{z} / \mathrm{D}=1.8$. The results indicate the excellent reproducibility as indicated by the agreement between the profiles at all radial positions in the bed. The error bars are small and the standard error obtained is 0.021 , which is very small, and here we confirm that the data from the CT are reproducible. 


\subsection{Solids and gas holdups of Case A}

\subsubsection{Solids holdups profiles for the Reference case (Case A)}

Figure 6 shows the radial profiles of solids holdup of Case A along the dimensionless heights (z/D) for the $0.152 \mathrm{~m}$ spouted bed. These profiles are obtained by azimuthally averaging the timeaveraged cross-sectional distribution of the measured solids holdup (Figure 7). It is pronounced that the solids holdup in the spout and the annulus regions of spouted bed is different. The annulus remains unchanged and has similar solids holdup profiles along the bed height of the spouted beds. The reason for this is that the solids move gradually and slowly downward by gravity in the annulus. In this region, the solids holdup radial profiles are nearly flat and have an average value of 0.6. This value is close to the maximum volume fraction of the solids holdup in the packing bed. In addition, those flat profiles suggest that the interaction between the wall and the particles in this region is small or neglected, explaining why this parameter was ignored by (He et al., 1997) in the first scaling relationship. In the spout, which is characterized as a gas-solid riser the solids holdup is lower near the gas inlet and increase as the height increases along the bed. This increase is because some solids enter the spout from the annulus at levels below the bed surface. The average of the solids holdup values in the spout increased by $28.91 \%$ from 0.8 to $1.1 \mathrm{z} / \mathrm{D}$, and by $49.8 \%$ from 0.8 to $1.8 \mathrm{z} / \mathrm{D}$. The solids holdup is lower near the center of the spout and gradually increases as the radial distance from the axis increases until it reaches the spout-annulus interface where the spout is confined by the annulus. The solids holdup profile in the fountain region is different from those obtained in the other regions of spouted beds. This is because the motion of the particles in this region is unique from the rest of the regions of the spouted bed where the particles are disengaged from the gas phase to recirculate back into the annulus. The amount of solids in the fountain region is important for the solids hydrodynamics and the solids 
circulation of spouted beds. As a result, the local solids holdup distribution was measured in this region to assess the scaling dimensionless groups. A maximum solids holdup was observed near the center of the fountain and decreased radially with increasing distance from the center. This radial decrease is expected due to the scatter of the particles in the radial direction of the fountain.

\subsubsection{Cross-sectional distribution of solids holdup for the Reference case (Case A)}

Figure 7 presents the measured time-averaged cross-sectional distributions and the corresponding frequency distribution of the solids holdup for the $0.152 \mathrm{~m}$ spouted beds at $\mathrm{z} / \mathrm{D}$ levels of $0.8,1.1,1.8$, and 2.4. The scale-bar on the right of the images indicates the fractions of the solids holdup. Red is indicative of a higher solids holdup, and blue is indicative of a lower solids holdup. The color distributions of the images clearly highlights the spout and the annulus regions. The cross-sectional images illustrate the unchanged value of the solids holdup in the annulus for all the z/D levels. As mentioned above, this is because the particles in this region are moving downward in a moving packed bed mode while feeding solids to the spout region. The frequency distribution of solids holdup is higher at the limit of the solids holdup at the annulus $\left(\varepsilon_{\mathrm{s}} \sim 0.6\right)$, and is skewed to the left where the frequency distributions are small in the spout region. A skewed distribution is expected for all levels due to smaller and larger solids holdup values in the spout and annulus regions, respectively. In addition, the asymmetrical distribution indicates a divergence between the spout and the annulus regions. The crosssectional distribution and the corresponding frequency distribution of solids holdup at the fountain region show the smaller solids holdup in the outer region of the fountain where particles fall back into the bed surface. This confirms the divergence between the three regions: the spout, the annulus, and the fountain. The frequency distribution in the fountain region, unlike other regions, is skewed to the right 
and thinner. This indicates that the solids holdup values are closer in the outer region of the fountain and have a small deviation among each other.

\subsubsection{Gas holdup profiles for the reference case (case A)}

Figure 8 shows the gas holdup profiles of Case A along the bed height of the $0.152 \mathrm{~m}$ spouted bed. They were obtained by $\varepsilon_{\mathrm{g}}=1-\varepsilon_{\mathrm{s}}$. It is demonstrated that the gas holdup is higher in the spout region, and has an even higher value near the gas inlet of the spouted bed, as the solids holdup in this level is small (about 0.08). It is observed in the spout region of both the solids holdup (Figure 6) and gas holdup (Figure 8) results that the gas holdup is higher in the bottom section of the bed (the cone) and decreases as the axial level of the bed increases. This decrease in gas holdup is because solids get into the spout from the annulus along the spout region. In the fountain region, the gas holdup is about 0.72 at the center and becomes higher in the outer region of the fountain where the particles fall back into the bed surface. Indeed, the two-phase flow behavior makes the structure of spouted beds complex. This complex structure significantly affects the movement of the solids in the entire bed as well as the gas-solids interaction since the three regions (the spout, the annulus, and the fountain) have a different flow structure from each other. Both the dilute region (the spout) and the dense region (the annulus) in spouted beds provide good interactions, contacts, and mixing of gas-solids, which provide evidence that spouted beds are desirable for many industrial applications including the TRISO nuclear fuel particle coating process.

\subsection{Demonstrating the non-similarity in local holdups with matching dimensionless groups}

In this section, the cross-sectional distribution of solids holdup, gas holdup, and their radial profiles are the chosen parameters for evaluating the dimensionless groups proposed by (He et al., 1997) for 
hydrodynamics similarity of spouted beds. By using the gamma-ray computed tomography (CT), a fully detailed phase distribution was obtained for Case A, Case B, and Case C. Correspondingly, the profiles for the solids and gas holdups were obtained in the spout, the annulus, and the fountain regions. It is important to note that obtaining the full picture of the phase distribution of spouted beds is not achievable form the use of other measurement techniques. The strategy of assessing the scaling groups for hydrodynamics similarity started with performing the CT scan for Case A (the reference case) and Case B. The conditions of Case A and Case B were originally selected to achieve matching dimensionless groups between the two cases. The dimensionless groups of Case B are matched as closely as possible to those of Case A, and both cases termed as cases of matching dimensionless groups.

The comparison of solids holdup profiles for Case A $(0.152 \mathrm{~m})$ and Case B $(0.076 \mathrm{~m})$ at different level of measurements are shown in Figure 9. From the figures, there is a good agreement in the solids holdup profiles between the cases of matching dimensionless groups, Case A and Case B, in the annulus as anticipated due to the structure of the flow in this region. The differences in the solids holdup profiles between the two cases are found in both the spout and fountain regions. At level $\mathrm{z} / \mathrm{D}=0.8$, the average relative difference between the two cases for all individual values in the spout region is $26.37 \%$. Near the center of the spout $(\mathrm{r} / \mathrm{R}=0.025)$, the difference is $42.88 \%$; at $\mathrm{r} / \mathrm{R}=0.125$ it is $49.31 \%$; at $\mathrm{r} / \mathrm{R}=0.225$ it is $20.03 \%$; at $\mathrm{r} / \mathrm{R}=0.325$, it is $8.62 \%$; and at $\mathrm{r} / \mathrm{R}=0.425$, it is $3.95 \%$. Note that near the spout-annulus interface, $\mathrm{r} / \mathrm{R} \sim 0.425$, the difference is less. The results of the two cases show that the solids holdup is lower near the center of the spout and gradually increases as the radial distance from the axis increases until the spout-annulus interface. At level $\mathrm{z} / \mathrm{D}=1.1$, the average relative difference for all individual values in the spout region between Case A and Case B is $25.02 \%$. The difference near the center of the spout $(\mathrm{r} / \mathrm{R}=0.025)$ is $39.02 \%$; at $\mathrm{r} / \mathrm{R}=0.125$ it was $34.71 \%$; at $\mathrm{r} / \mathrm{R}=0.225$ it is $23.27 \%$; at $\mathrm{r} / \mathrm{R}=0.325$ it is 
$14.85 \%$; and at $\mathrm{r} / \mathrm{R}=0.425$ the difference is $4.33 \%$. At level $\mathrm{z} / \mathrm{D}=1.8$, which is below the bed surface, the average relative difference in the spout region is $15.26 \%$. Near the center of the spout, the difference is $16.87 \%$; at $\mathrm{r} / \mathrm{R}=0.125$, it is $21.66 \%$; at $\mathrm{r} / \mathrm{R}=0.225$, it is $19.95 \%$; at $\mathrm{r} / \mathrm{R}=0.325$, it is $11.71 \%$; and at $\mathrm{r} / \mathrm{R}=0.425$ it is $4.24 \%$. The average relative difference between the profiles in the fountain region is $24.92 \%$. Indeed, the average difference for the levels will be enough to indicate the difference among the measured solids holdup for Case A and Case B. Therefore, the similarity in solids and gas holdups (gas holdup $=1$-solids holdup) distribution is not achieved despite the matching of these proposed dimensionless groups.

The evolution of solids holdup cross-sectional distribution of spouted beds should provide valuable information concerning the assessment of the scaling relationships. Figure 10 shows the measured timeaveraged cross-sectional distribution and the corresponding frequency distribution of the solids holdup for Case B $(0.076 \mathrm{~m})$ at the $\mathrm{z} / \mathrm{D}$ levels of $0.8,1.1,1.8$, and 2.4. The maximum of the color scale were kept equal to those of Case A for connivance comparison between the images. The color distribution of the images clearly highlights the spout and the annulus regions for the $0.076 \mathrm{~m}$ spouted bed. The crosssectional images demonstrate the unchanged value of the solids holdup in the annulus for Case B for all the z/D levels and further confirm the similarity of the solids holdup profiles between Case A and Case B in this region. However, difference can be observed between the images in the spout region (in strict sense) of the two beds. This difference becomes more obvious, if we take into consideration the frequency distribution of the local solids holdup values in terms of mean, standard deviation, and shape for Case A and Case B. At $\mathrm{z} / \mathrm{D}=0.8$, the mean of the solids holdup frequency distribution is 0.56 and 0.54 , for Case A and Case B, respectively. Note that the statistical analysis of the holdups distribution is impacted by the solids holdup values of both the spout and the annulus regions. At $\mathrm{z} / \mathrm{D}=1.1$, the mean of the solids holdup frequency distribution is 0.57 and 0.56 , for Case A and Case $\mathrm{B}$, 
respectively. At $\mathrm{z} / \mathrm{D}=1.8$, the mean of the solids holdups frequency distribution is 0.58 and 0.57 , for Case A and Case B, respectively. Difference is also found between the two cases in the fountain region. In the fountain, the mean of the solids holdup distribution is 0.07 and 0.1 , for Case A and Case B, respectively. By analyzing the above discussion and the data obtained one may draw conclusion that the similarity in the solids and gas holdups distributions in terms of mean, standard deviation and shape are not achieved when the dimensionless groups are matched between the two beds. This indicates that the suggested scale-up methodology based on matching dimensionless groups is inadequate for the successful scale-up of gas-solids spouted bed.

The comparison of gas holdup radial profiles at different axial levels for Case A (0.152 m) and Case B $(0.076 \mathrm{~m})$ are shown in Figure 11. It is more evident that the gas holdup near the center of the spout is higher than in the annulus. In the spout, the gas holdup is higher near the gas inlet (cone section) and decreases with increasing the bed height. This decrease is due to the increase in the solids holdup towards the fountain region. Near the center of the spout, the gas holdup is higher and decreases gradually towards the spout-annulus interface. The average value of the gas holdup in the annulus was found to be constant $\varepsilon_{\mathrm{g}}=0.4$. The absolute percentage differences between the profiles are compared for all the $\mathrm{z} / \mathrm{D}$ levels. The average relative percentage differences for all the individual values of gas holdup in the spout region for matched dimensionless groups are $7.62 \%, 12.57 \%$, and $11.88 \%$, at z/D levels of 0.8 , 1.1 , and 1.8, respectively. The average difference between the profiles in the fountain region is $6.57 \%$. From the results analysis, the similarity in gas holdup profiles is not achieved despite matching the proposed dimensionless groups. This further indicates that the hydrodynamics of spouted beds are not fully predicted by matching these groups. 


\subsection{The non-similarity in local holdups with mismatching dimensionless groups}

The examination of different operating conditions with mismatch scaling groups is necessary in order to assess the scaling relationships for scale-up of spouted beds. The conditions of Case $\mathrm{C}$ are conducted to examine the influence of mismatched scaling groups. Case $\mathrm{C}$ is also proposed to study the common unsuitable scale-up criteria through varying only the bed dimensions to achieve geometrical similarity while other scaling groups are not matched. Figure 12 shows the comparison of solids holdup profiles for Case A $(0.152 \mathrm{~m})$ and Case $\mathrm{C}(0.076 \mathrm{~m})$ at $\mathrm{z} / \mathrm{D}$ levels of $0.8,1.1,1.8$, and 2.4. The results show that the solids holdup profiles of the two beds deviate from each other substantially in the spout and fountain regions, and have similar profiles in the annulus. The absolute percentage differences between the profiles of the two beds have been evaluated. At $\mathrm{z} / \mathrm{D}=0.8$, the relative average percentage difference between the two cases for all individual values in the spout region is $46.26 \%$. Near the center of the spout $(\mathrm{r} / \mathrm{R}=0.025)$, the difference is $65.92 \%$; at $\mathrm{r} / \mathrm{R}=0.125$, it is $72.59 \%$; at $\mathrm{r} / \mathrm{R}=0.225$, it is $55 \%$; at $\mathrm{r} / \mathrm{R}=0.325$, it is $22.07 \%$; and at $\mathrm{r} / \mathrm{R}=0.425$, it is $5.08 \%$. At $\mathrm{z} / \mathrm{D}=1.1$, the average relative difference in the spout region between Case A and Case C is $44.29 \%$. The difference near the center of the spout is $67.3 \%$ at $\mathrm{r} / \mathrm{R}=0.025$; at $\mathrm{r} / \mathrm{R}=0.125$, it is $68.08 \%$; at $\mathrm{r} / \mathrm{R}=0.225$, it is $50.46 \%$; at $\mathrm{r} / \mathrm{R}=0.325$, it is $24.05 \%$; and at $\mathrm{r} / \mathrm{R}=0.425$, it is $5.17 \%$. At $\mathrm{z} / \mathrm{D}=1.8$, the average relative difference between the profiles in the spout region is $38.12 \%$. The difference in the spout is $55.75 \%$ at $\mathrm{r} / \mathrm{R}=0.025$; at $\mathrm{r} / \mathrm{R}=0.125$, it is $55.4 \%$; at $\mathrm{r} / \mathrm{R}=0.225$, it is $45.8 \%$; at $\mathrm{r} / \mathrm{R}=0.325$, it is $23.96 \%$; and at $\mathrm{r} / \mathrm{R}=0.425$, it is $4.9 \%$. The average relative percentage difference between the profiles in the fountain region is $22.43 \%$. By realizing the solids holdup profiles for mismatch dimensionless groups, it is not sufficient to achieve good hydrodynamics similarity between the two beds by matching only the beds and particles dimensionless groups. However, matching all the dimensionless groups of spouted beds is difficult since many parameters are included especially when it comes to industry for those of large columns. 
Figure 13 shows the measured time-averaged cross-sectional distribution and the corresponding frequency distribution of the solids holdup for Case $\mathrm{C}(0.076 \mathrm{~m})$ at $\mathrm{z} / \mathrm{D}$ levels of $0.8,1.1,1.8$, and 2.4. The color distribution of the images clearly highlights the spout and the annulus regions for the $0.076 \mathrm{~m}$ spouted bed. The cross-sectional images show the unchanged solids holdup value in the annulus for Case $\mathrm{C}$ at all the z/D levels and further confirm the similarity of the solids holdup profiles between Case $\mathrm{A}$ and Case $\mathrm{C}$ in this region. However, difference can be observed between the images in the spout region (in the strict sense) of the two beds. This difference becomes more obvious, if we consider the frequency distribution of the local solids holdup values in terms of mean, standard deviation, and shape for Case A and Case B. At $\mathrm{z} / \mathrm{D}=0.8$, the mean of the solids holdups frequency distribution is 0.56 and 0.54 , for Case $\mathrm{A}$ and Case $\mathrm{C}$, respectively. At $\mathrm{z} / \mathrm{D}=1.1$, the mean of the solids holdups frequency distribution is 0.57 and 0.55 , for Case $A$ and Case $C$, respectively. While at $\mathrm{z} / \mathrm{D}=1.8$, the mean of the solids holdups frequency distribution is 0.583 and 0.564 , for Case A and Case C, respectively. Difference is also found between the two cases in the fountain region where the mean of the solids holdup distribution is 0.073 and 0.0672, respectively, for Case A and Case C. From the results above, matching only the beds and particles dimensionless groups are not sufficient for achieving good hydrodynamics similarity between the two beds.

Figure 14 shows the comparison of gas holdup profiles for Case A $(0.152 \mathrm{~m})$ and Case C (0.076 $\mathrm{m})$ at $\mathrm{z} / \mathrm{D}$ levels of $0.8,1.1,1.8$, and 2.4. The relative percentage difference between the profiles of Case A and Case $\mathrm{C}$ were evaluated at all $\mathrm{z} / \mathrm{D}$ levels. The average relative percentage difference for all the individual values of gas holdup in the spout region for mismatched dimensionless groups is $13.47 \%$, $20.53 \%$, and $24.25 \%$, at z/D levels of $0.8,1.1$, and 1.8 , respectively. The average percentage between the profiles in the fountain region is $7.36 \%$. The results above indicate the differences in the gas holdup profiles between the two beds for mismatch dimensionless groups. 


\section{Conclusions}

The key conclusion drawn from the results of this work is that the dimensionless groups proposed by (He et al., 1997) are not sufficient to maintain similarity in local solids and gas holdups distributions along the bed height by implementing gamma-ray computed tomography (CT) as an advanced noninvasive technique using the studied gas-solid spouted beds of $0.076 \mathrm{~m}$ and $0.152 \mathrm{~m}$ diameter. Adding more dimensionless groups to match in order to capture the other interplay phenomena will further complicate the scale-up methodology since it will be not easy to define the conditions between two scales to match large number of dimensionless groups. This is because of the complex flow pattern of spouted beds arising from complex interactions among the solids and between the solids and the gas phases. This necessitates the need to measure the other local parameters, such as solids velocity field and the associated turbulent parameters to properly and further evaluate such a method for scale-up of spouted beds. Furthermore, a new mechanistic scale-up methodology needs to be developed which could be based on identifying the key parameter(s) that dictate the dynamics of the bed such as gas holdup radial profiles.

Our results have also demonstrated that in the spout region the solids holdup increases along the height of the spouted bed. This is because the solids are being pulled by the jet of the gas phase at the interface between the spout and the annulus along the spout height. In the annulus, the solids move downward as a moving bed. Hence, the solids holdup does not change along the bed height. The structure of the solids holdup distributions in the annular region is clearly distinguished from the spout and fountain regions.

It is worth mentioning that the reported data is valuable to benchmark CFD and DEM simulations and to validate the selected set models and closures. 


\section{Acknowledgment}

US Department of Energy - Nuclear Energy Research Initiative (DOE-NERI) grant (NERI DEFC0707ID14822), the GAANN, chancellor fellowship, and professor Al-Dahhan's Lab Fund are acknowledged for the financial support that made this work possible. The second author would like to thank the King Abdulaziz City for Science and Technology (KACST) for sponsoring his Ph.D. studies at Missouri S\&T. 


\section{Notation}

$d_{p} \quad$ particle diameter, $\mathrm{m}$

D inner column diameter, $\mathrm{m}$

$D_{c} \quad$ inner column diameter, $\mathrm{m}$

$D_{i} \quad$ inlet orifice diameter, $\mathrm{m}$

$e_{s s} \quad$ restitution coefficient of the particles

$\mathrm{Fr} \quad$ Froude number

$g \quad$ acceleration due to gravity, $\mathrm{m} \mathrm{s}^{-2}$

$H \quad$ static bed height, $\mathrm{m}$

$H$. initial height, $\mathrm{m}$

$H_{1} \quad$ particle rebounding height, $\mathrm{m}$

$H_{F} \quad$ fountain height, m

$H_{m} \quad$ maximum spoutable bed depth, m

$h(y \mid x)$ length of the segment of projection y in pixel $\mathrm{x}(\mathrm{cm})$

I the intensity of radiation

$I_{o}(\mathrm{y}) \quad$ the incident radiation intensity

I(y) the radiation intensity detected after passing through the chord length

L column length, $\mathrm{m}$

$P \quad$ bed pressure, $\mathrm{Pa}$

Re Reynolds number

$R \quad$ column radius, $\mathrm{cm}$

$r \quad$ radial position, $\mathrm{cm}$

$T \quad$ bed temperature, $\mathrm{K}$ 
$U \quad$ superficial gas velocity, $\mathrm{m} \mathrm{s}^{-1}$

$U_{m f} \quad$ minimums fluidization velocity, $\mathrm{m} \mathrm{s}^{-1}$

$U_{m s} \quad$ minimum spouting velocity, $\mathrm{m} \mathrm{s}^{-1}$

$\mathrm{x} \quad$ index for pixel in image domain

y index for projection or source detector pair

$\mathrm{z} \quad$ axial distance form inlet orifice, $\mathrm{m}$

\section{Greek letters}

$\beta \quad$ fluid-particle interaction coefficient, $\mathrm{kg} \mathrm{m}^{3} \mathrm{~s}^{-1}$

$\rho_{s} \quad$ particle density, $\mathrm{Kg} \mathrm{m}^{-3}$

$\rho_{f} \quad$ fluid density, $\mathrm{Kg} \mathrm{m}^{-3}$

$\mu \quad$ fluid viscosity, $\mathrm{Kg} \mathrm{m}^{-1} \mathrm{~s}^{-1}$

$\phi_{s} \quad$ sphericity of particles

$\varphi \quad$ internal friction angle of particle, deg

$\varepsilon_{m f} \quad$ bed voidage at minimum fluidization

$\varepsilon_{o} \quad$ voidage at packed bed state

$\varepsilon_{s} \quad$ solids phase fraction (or solids holdup)

$\varepsilon_{g} \quad$ gas holdup fraction (or gas holdup)

$\hat{\mu}(x)$ attenuation values estimated by the AM algorithm for a given pixel $\mathrm{x}, \mathrm{cm}^{-1}$.

$\hat{\mu}_{\mathrm{s}}(x)$ attenuation values when the system filled with solids and spouting gas is absent, $\mathrm{cm}^{-1}$.

$\hat{\mu}_{\mathrm{g}}(x)$ attenuation values for pure gas phase (empty column), $\mathrm{cm}^{-1}$.

$\hat{\mu}_{\mathrm{s}-\mathrm{g}}(x)$ attenuation value for the gas-solids when the system is dynamic at the desired operating condition, $\mathrm{cm}^{-1}$. 


\section{References}

Ahmed, F.S.,2014. Experimental investigation of the pebble bed structure by using gamma-ray tomography. Masters Theses. Paper 7317. http://scholarsmine.mst.edu/masters_theses/7317.

Al-Dahhan, M.H., 2009. Radioisotopes applications in industry: an overview. Atoms for Peace: an International Journal 2, 324-337.

Al-Dahhan, M.H., Kemoun, A., Cartolano, A.R., Roy, S., Dobson, R., Williams, J., 2007. Measuring gas-liquid distribution in a pilot scale monolith reactor via an Industrial Tomography Scanner (ITS). Chemical Engineering Journal 130, 147-152.

Aradhya, S.B., 2013. Scaleup and hydrodynamics study of gas-solid spouted beds, Doctoral Dissertations. Paper 2254. http://scholarsmine.mst.edu/doctoral_dissertations/2254/.

Béttega, R., Corrêa, R.G., Freire, J.T., 2009. Scale-up study of spouted beds using computational fluid dynamics. The Canadian Journal of Chemical Engineering 87, 193-203.

Bhusarapu, S., Al-Dahhan, M.H., Duduković, M.P., 2006. Solids flow mapping in a gas-solid riser: Mean holdup and velocity fields. Powder Technology 163, 98-123.

Chandnani, P.P., Epstein, N., 1986. Spoutability and spout detabilization of fine particles with a gas. Engineering Foundation, United States.

Chen, J., Kemoun, A., Al-Dahhan, M.H., Duduković, M.P., Lee, D.J., Fan, L.-S., 1999. Comparative hydrodynamics study in a bubble column using computer-automated radioactive particle tracking (CARPT)/computed tomography (CT) and particle image velocimetry (PIV). Chemical Engineering Science 54, 2199-2207.

Csiszár, I., 1975. I-divergence geometry of probability distributions and minimization problems. The Annals of Probability 3, 146-158.

Du, W., Bao, X., Xu, J., Wei, W., 2006. Computational fluid dynamics (CFD) modeling of spouted bed: Assessment of drag coefficient correlations. Chemical Engineering Science 61, 1401-1420.

Du, W., Xu, J., Ji, Y., Wei, W., Bao, X., 2009. Scale-up relationships of spouted beds by solid stress analyses. Powder Technology 192, 273-278.

Duarte, C.R., Murata, V.V., Barrozo, M.A.S., 2005. Simulation of Spouted Bed Using a Eulerian Multiphase Model. Materials Science Forum 498-499, 270-277.

Duarte, C.R., Olazar, M., Murata, V.V., Barrozo, M.A.S., 2009. Numerical simulation and experimental study of fluidparticle flows in a spouted bed. Powder Technology 188, 195-205.

Glicksman, L.R., 1984. Scaling relationships for fluidized beds. Chemical Engineering Science 39, $1373-1379$.

Gryczka, O., Heinrich, S., Deen, N.G., van Sint Annaland, M., Kuipers, J.A.M., Jacob, M., Mörl, L., 2009a. Characterization and CFD-modeling of the hydrodynamics of a prismatic spouted bed apparatus. Chemical Engineering Science 64, 3352-3375.

Gryczka, O., Heinrich, S., Deen, N.G., van Sint Annaland, M., Kuipers, J.A.M., Mörl, L., 2009b. CFD modeling of a prismatic spouted bed with two adjustable gas inlets. The Canadian Journal of Chemical Engineering 87, 318-328.

He, Y.L., Lim, C.J., Grace, J.R., 1992. Spouted bed and spout-fluid bed behaviour in a column of diameter $0.91 \mathrm{~m}$. The Canadian Journal of Chemical Engineering 70, 848-857.

He, Y.L., Lim, C.J., Grace, J.R., 1997. Scale-up studies of spouted beds. Chemical Engineering Science 52, $329-339$.

Hosseini, S.H., Ahmadi, G., Olazar, M., 2013. CFD simulation of cylindrical spouted beds by the kinetic theory of granular flow. Powder Technology 246, 303-316.

Kemoun, A., Cheng Ong, B., Gupta, P., Al-Dahhan, M.H., Dudukovic, M.P., 2001. Gas holdup in bubble columns at elevated pressure via computed tomography. International Journal of Multiphase Flow 27, 929-946.

Kumar, S.B., Moslemian, D., Duduković, M.P., 1995. A $\gamma$-ray tomographic scanner for imaging voidage distribution in two-phase flow systems. Flow Measurement and Instrumentation 6, 61-73.

Lan, X., Xu, C., Gao, J., Al-Dahhan, M., 2012. Influence of solid-phase wall boundary condition on CFD simulation of spouted beds. Chemical Engineering Science 69, 419-430.

Lee, Y.-W., Park, J.-Y., Kim, Y.K., Jeong, K.C., Kim, W.K., Kim, B.G., Kim, Y.M., Cho, M.S., 2008. Development of HTGR-coated particle fuel technology in Korea. Nuclear Engineering and Design 238, 2842-2853.

Li, Y., Che, D., Liu, Y., 2012. CFD simulation of hydrodynamic characteristics in a multiple-spouted bed. Chemical Engineering Science 80, 365-379.

Lim, C.J., Grace, J.R., 1987. Spouted bed hydrodynamics in a $0.91 \mathrm{~m}$ diameter vessel. The Canadian Journal of Chemical Engineering 65, 366-372. 
Liu, M., Shao, Y., Liu, B., 2012. Pressure analysis in the fabrication process of TRISO UO2-coated fuel particle. Nuclear Engineering and Design 250, 277-283.

Liu, Y.-J., Li, W., Han, L.-C., Cao, Y., Luo, H.-a., Al-Dahhan, M., Dudukovic, M.P., 2011. $\gamma$-CT measurement and CFD simulation of cross section gas holdup distribution in a gas-liquid stirred standard Rushton tank. Chemical Engineering Science 66, 3721-3731.

Luo, H.-P., Al-Dahhan, M.H., 2010. Local gas holdup in a draft tube airlift bioreactor. Chemical Engineering Science 65, 4503-4510.

Mathur, K.B., Epstein, N., 1974a. 1 - Introduction, in: Mathur, K.B., Epstein, N. (Eds.), Spouted Beds. Academic Press, pp. 1-13.

Mathur, K.B., Epstein, N., 1974b. 6 - Spouting Stability, in: Mathur, K.B., Epstein, N. (Eds.), Spouted Beds. Academic Press, pp. 112-124.

Mesfer, M. A., 2013. Effect of Dense Heat Exchanging Internals on the Hydrodynamics of Bubble Column Reactors Using Non-invasive Measurement Techniques. Doctoral Dissertations. Paper 27.

http://scholarsmine.mst.edu/doctoral_dissertations/27.

Moradi, S., Yeganeh, A., Salimi, M., 2013. CFD-modeling of effects of draft tubes on operating condition in spouted beds. Applied Mathematical Modelling 37, 1851-1859.

O'Sullivan, J.A., Benac, J., 2007. Alternating minimization algorithms for transmission tomography. IEEE Transactions on Medical Imaging 26, 283-297.

Prasser, H.M., Baldauf, D., Fietz, J., Hampel, U., Hoppe, D., Zippe, C., Zschau, J., Christen, M., Will, G., 2003. Time resolving gamma-tomography for periodically changing gas fraction fields and its application to an axial pump. Flow Measurement and Instrumentation 14, 119-125.

Rados, N., Shaikh, A., Al-Dahhan, M.H., 2005. Solids flow mapping in a high pressure slurry bubble column. Chemical Engineering Science 60, 6067-6072.

Ren, B., Zhong, W., Jin, B., Yuan, Z., Lu, Y., 2011. Computational Fluid Dynamics (CFD)-Discrete Element Method (DEM) Simulation of Gas-Solid Turbulent Flow in a Cylindrical Spouted Bed with a Conical Base. Energy \& Fuels 25, 4095-4105.

Rong, L.-W., Zhan, J.-M., 2010. Improved DEM-CFD model and validation: A conical-base spouted bed simulation study. Journal of Hydrodynamics, Ser. B 22, 351-359.

Roy, S., Al-Dahhan, M., 2005. Flow distribution characteristics of a gas-liquid monolith reactor. Catalysis Today 105, 396-400.

Roy, S., Kemoun, A., Al-Dahhan, M.H., Dudukovic, M.P., Skourlis, T.B., Dautzenberg, F.M., 2005. Countercurrent flow distribution in structured packing via computed tomography. Chemical Engineering and Processing: Process Intensification 44, 59-69.

Sawa, K., Ueta, S., 2004. Research and development on HTGR fuel in the HTTR project. Nuclear Engineering and Design 233, 163-172.

Shaikh, A., Al-Dahhan, M., 2005. Characterization of the hydrodynamic flow regime in bubble columns via computed tomography. Flow Measurement and Instrumentation 16, 91-98.

Shuyan, W., Xiang, L., Huilin, L., Long, Y., Dan, S., Yurong, H., Yonglong, D., 2009. Numerical simulations of flow behavior of gas and particles in spouted beds using frictional-kinetic stresses model. Powder Technology 196, 184-193.

Sokolovskii, V., 1965. Statistics of granular media. Pergamon Press, Oxford.

Tang, C., Tang, Y., Zhu, J., Zou, Y., Li, J., Ni, X., 2002. Design and manufacture of the fuel element for the $10 \mathrm{MW}$ high temperature gas-cooled reactor. Nuclear Engineering and Design 218, 91-102.

Varma, R., 2008. Characterization of anaerobic bioreactors for bioenergy generation using a novel tomography technique. Doctoral Dissertations. Washington University. Dept. of Energy, Environmental and Chemical Engineering.

Varma, R., Bhusarapu, S., Sullivan, J.A.O., Al-Dahhan, M.H., 2008. A comparison of alternating minimization and expectation maximization algorithms for single source gamma ray tomography. Measurement Science and Technology 19, 015506.

Wang, S., Zhao, L., Wang, C., Liu, Y., Gao, J., Liu, Y., Cheng, Q., 2014. Numerical simulation of gas-solid flow with two fluid model in a spouted-fluid bed. Particuology 14, 109-116.

Wang, Z.G., Bi, H.T., Lim, C.J., 2006. Numerical simulations of hydrodynamic behaviors in conical spouted beds. China Particuology 4, 194-203.

Yang, S., Luo, K., Fang, M., Zhang, K., Fan, J., 2014. Parallel CFD-DEM modeling of the hydrodynamics in a lab-scale double slot-rectangular spouted bed with a partition plate. Chemical Engineering Journal 236, 158-170. 
Zhonghua, W., Mujumdar, A.S., 2008. CFD modeling of the gas-particle flow behavior in spouted beds. Powder Technology 183, 260-272. 


\section{Table captions}

Table 1. Dimensional parameters and properties of scale-up verification conditions from the work of (He et al., 1997). (He et al., 1997). 


\section{Figure captions}

Figure 1. Schematic diagram of spouted beds.

Figure 2. Schematic diagram of $0.076 \mathrm{~m}$ and $0.152 \mathrm{~m}$ spouted beds.

Figure 3. Photograph of the DSCT technique, and $0.152 \mathrm{~m}$ spouted bed inside the setup for scan.

Figure 4. The computational domain is discretized into cells of size $\mathrm{x}$.

Figure 5. Reproducibility of CT measurements for (a) cross-sectional solids holdup distributions and (b) their radial profiles with the associated error bars for three CT scans at $\mathrm{z} / \mathrm{D}=1.8$ (Conditions; Case A in Table 1).

Figure 6. Radial profiles of solids holdup along the bed height of the $0.152 \mathrm{~m}$ spouted bed using conditions in Case A (reference case) listed in Table 1.

Figure 7. Cross-sectional distribution and corresponding frequency distribution of solids holdup for Case A along the bed height of the $0.152 \mathrm{~m}$ spouted bed.

Figure 8. Radial profiles of gas holdup along the bed height of the $0.152 \mathrm{~m}$ spouted bed using conditions in Case A (reference case)

Figure 9. Comparison of radial profiles of solids holdup at z/D levels of 0.8, 1.1, 1.8, and 2.4 for Case A $(0.152 \mathrm{~m})$ and Case B $(0.076 \mathrm{~m})$ spouted beds.

Figure 10. Cross-sectional image and corresponding frequency distribution of solids holdup for Case B along the bed height of the $0.076 \mathrm{~m}$ spouted bed.

Figure 11. Comparison of radial profiles of gas holdup at z/D levels of 0.8, 1.1, 1.8, and 2.4 for Case A $(0.152 \mathrm{~m})$ and Case B $(0.076 \mathrm{~m})$ spouted beds.

Figure 12. Comparison of radial profiles of solids holdup at z/D levels of $0.8,1.1,1.8$, and 2.4 for Case A $(0.152 \mathrm{~m})$ and Case C $(0.076 \mathrm{~m})$ spouted beds. 
Figure 13. Cross-sectional image and corresponding frequency distribution of solids holdup for Case C along the bed height of the $0.076 \mathrm{~m}$ spouted bed.

Figure 14. Comparison of radial profiles of gas holdup at z/D levels of 0.8, 1.1, 1.8, and 2.4 for Case A $(0.152 \mathrm{~m})$ and Case C $(0.076 \mathrm{~m})$ spouted beds. 
Table 1. Dimensional parameters and properties of scale-up verification conditions from the work of (He et al., 1997).

\begin{tabular}{|c|c|c|c|}
\hline Condition/Case & A & B & $\mathrm{C}$ \\
\hline$D_{c}(\mathrm{~m})$ & 0.152 & 0.076 & 0.076 \\
\hline$D_{i} \times 10^{3}(\mathrm{~m})$ & 19.1 & 9.5 & 9.5 \\
\hline$L \quad(\mathrm{~m})$ & 1.14 & 1.14 & 1.14 \\
\hline$H(\mathrm{~m})$ & 0.323 & 0.16 & 0.16 \\
\hline$T(\mathrm{~K})$ & 298 & 298 & 298 \\
\hline$P \quad(\mathrm{kPa})$ & 101 & 312 & 101 \\
\hline Particles & Glass & Steel & Glass \\
\hline$d_{p} \times 10^{3}(\mathrm{~m})$ & 2.18 & 1.09 & 1.09 \\
\hline$\rho_{s}\left(\mathrm{~kg} / \mathrm{m}^{3}\right)$ & 2400 & 7400 & 2450 \\
\hline$\rho_{f}\left(\mathrm{~kg} / \mathrm{m}^{3}\right)$ & 1.21 & 3.71 & 1.21 \\
\hline$\mu\left(\mathrm{x} \mathrm{10^{5 } )} \quad(\mathrm{Pa} . \mathrm{s})\right.$ & 1.81 & 1.81 & 1.81 \\
\hline$U(\mathrm{~m} / \mathrm{s})$ & 1.08 & 0.75 & 0.74 \\
\hline \multicolumn{4}{|l|}{ Scaling groups } \\
\hline$\phi_{s}$ & 1 & 1 & 1 \\
\hline$\varphi\left(^{\circ}\right)$ & 26 & 28 & 27 \\
\hline$\varepsilon_{m f}$ & 0.41 & 0.42 & 0.42 \\
\hline$H / D_{c}$ & 2.1 & 2.1 & 2.1 \\
\hline$D_{c} / D_{i}$ & 8 & 8 & 8 \\
\hline$D_{c} / d_{p}$ & 70 & 70 & 70 \\
\hline$\rho_{s} / \rho_{f}$ & 1994 & 1995 & 2029 \\
\hline$R e=\rho_{f} d_{p} U / \mu$ & 157 & 168 & 54 \\
\hline$F r=U^{2} / g d_{p}$ & 54.5 & 52.6 & 51.2 \\
\hline$\rho_{s} d_{p} U / \mu\left(x 10^{-3}\right)$ & 313 & 334 & 109 \\
\hline$U^{2} / g D_{c}$ & 0.78 & 0.75 & 0.73 \\
\hline$U / U_{m f}$ & 0.95 & 0.92 & 0.16 \\
\hline$U / U_{m s}$ & 0.93 & 0.92 & 0.9 \\
\hline
\end{tabular}




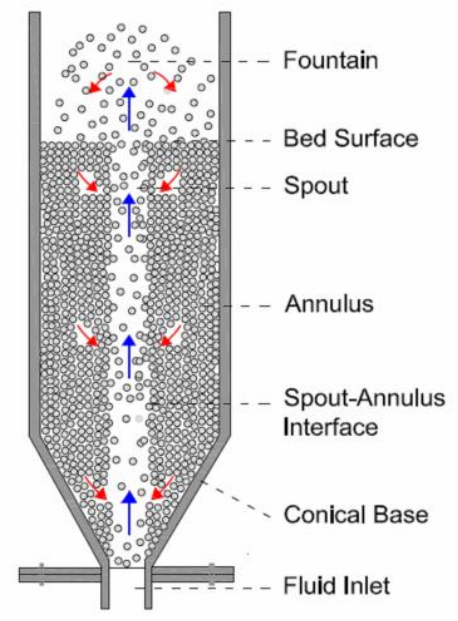

Figure 1. Schematic diagram of spouted beds. 

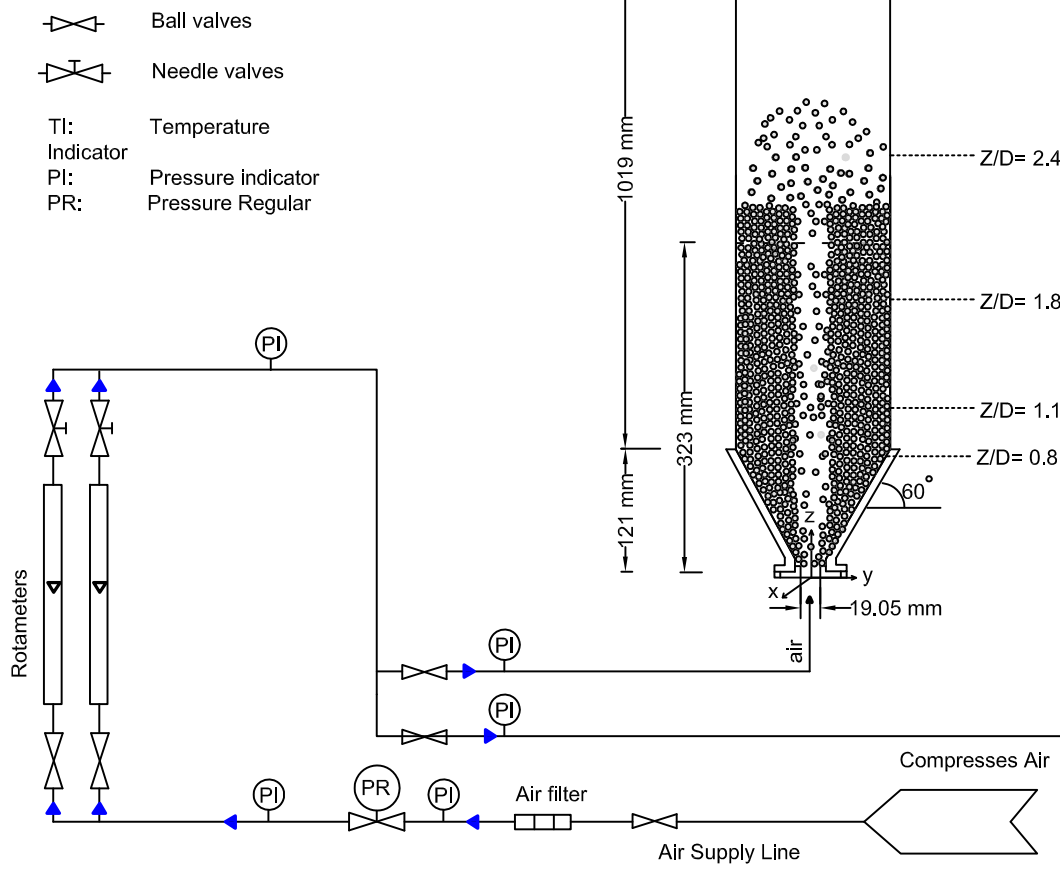

(PI)

Figure 2. Schematic diagram of $0.076 \mathrm{~m}$ and $0.152 \mathrm{~m}$ spouted beds. 


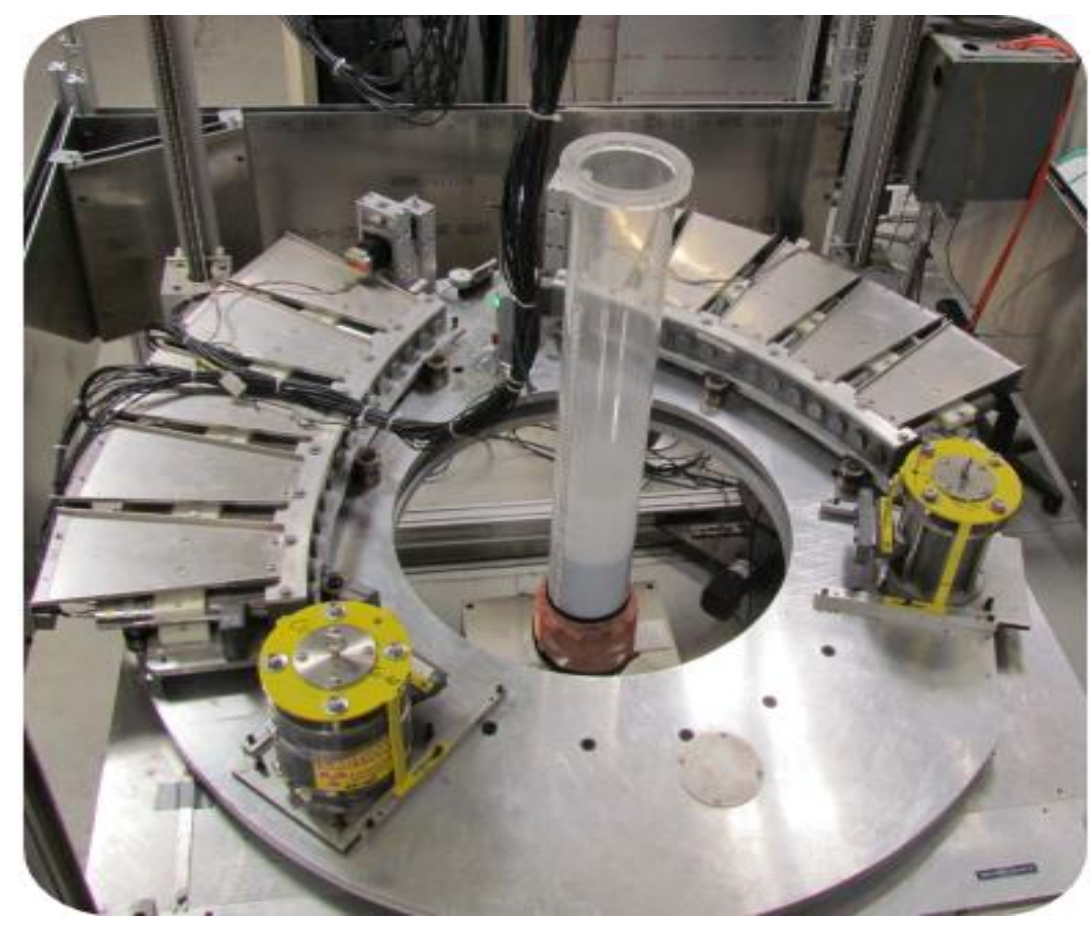

Figure 3. Photograph of the DSCT technique, and $0.152 \mathrm{~m}$ spouted bed inside the setup for scan. 


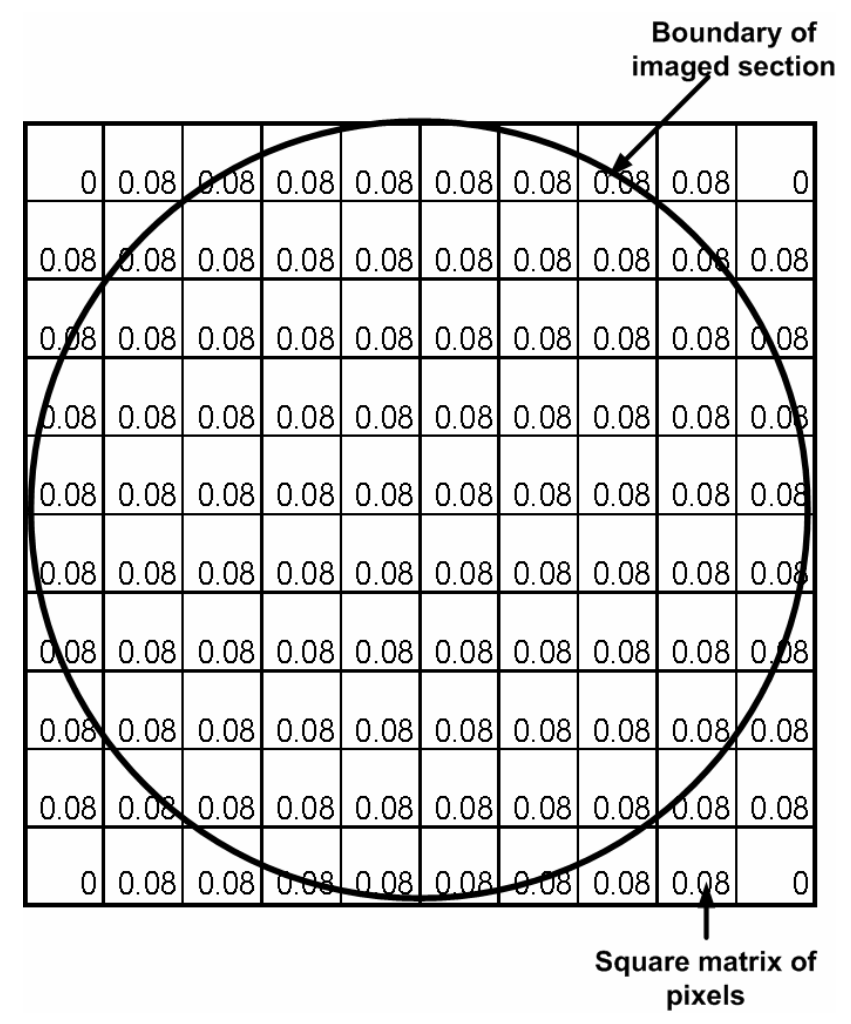

Figure 4. The computational domain is discretized into cells of size $\mathrm{x}$. 

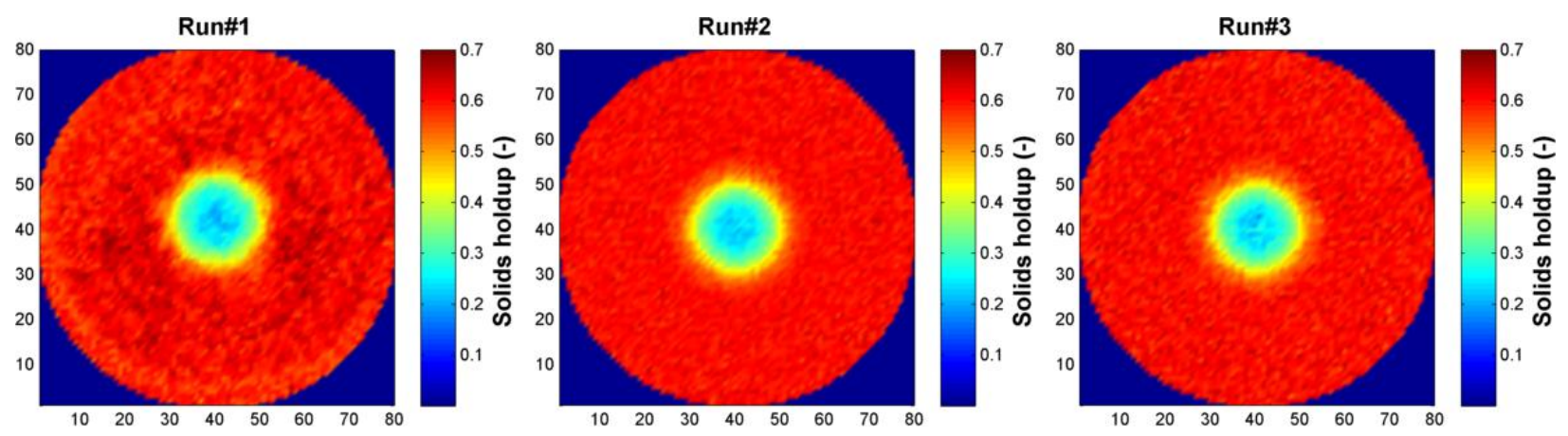

(a)

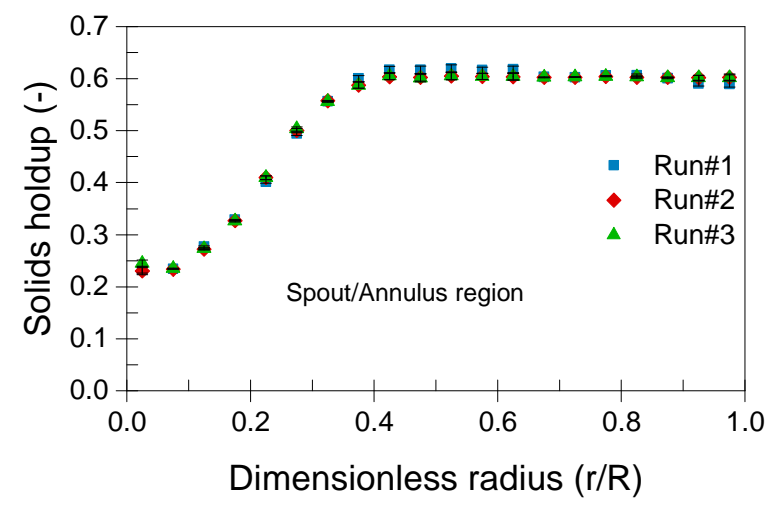

(b)

Figure 5. Reproducibility of CT measurements for (a) cross-sectional solids holdup distributions and (b) their radial profiles with the associated error bars for three $\mathrm{CT}$ scans at $\mathrm{z} / \mathrm{D}=1.8$ (Conditions; Case A in Table 1). 

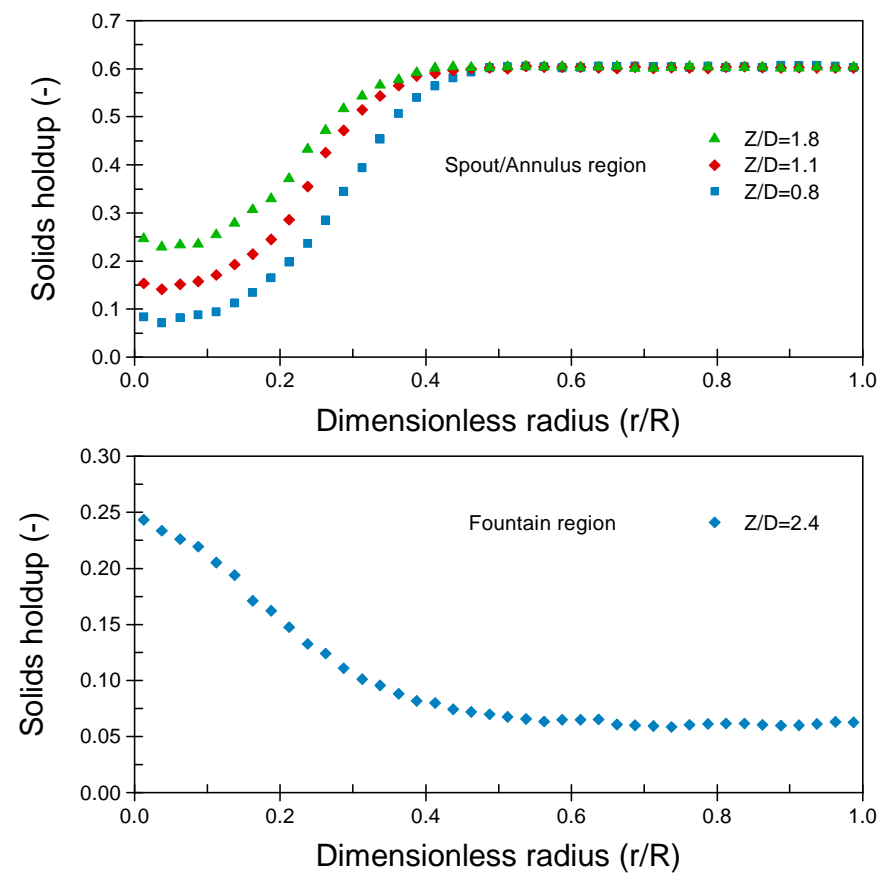

Figure 6. Radial profiles of solids holdup along the bed height of the $0.152 \mathrm{~m}$ spouted bed using conditions in Case A (reference case) listed in Table 1. 

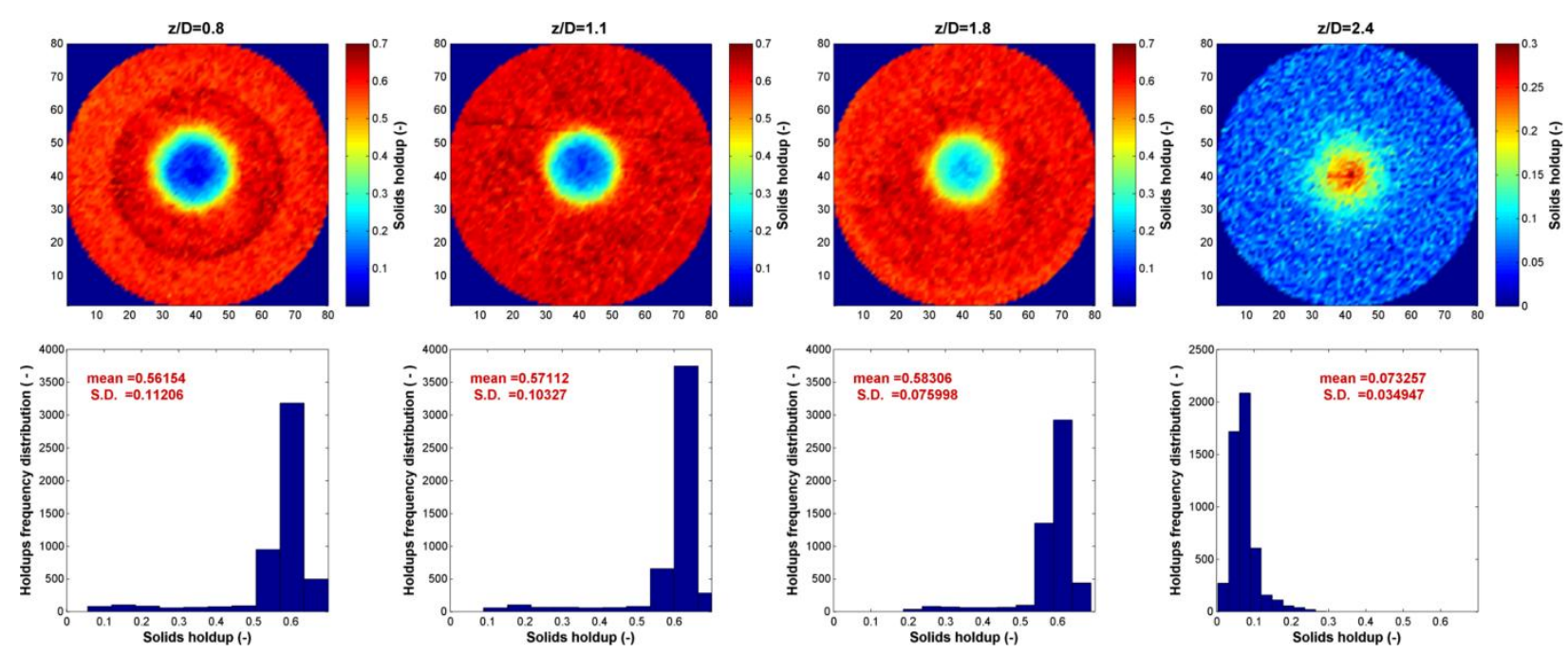

Figure 7. Cross-sectional distribution and corresponding frequency distribution of solids holdup for Case A along the bed height of the $0.152 \mathrm{~m}$ spouted bed. 

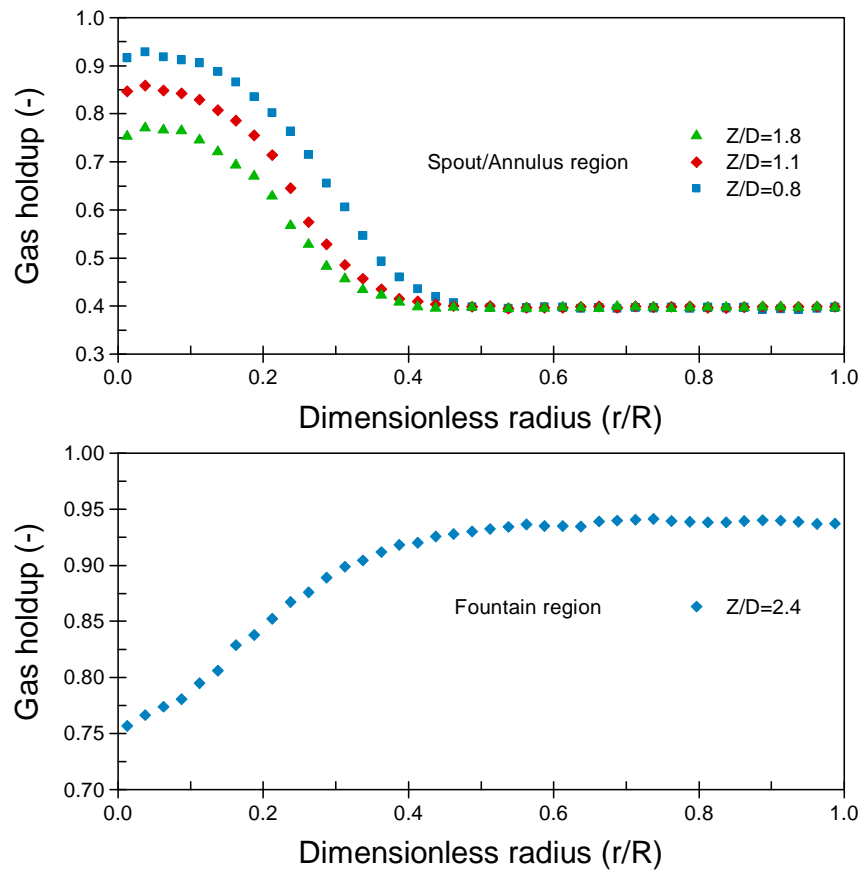

Figure 8. Radial profiles of gas holdup along the bed height of the $0.152 \mathrm{~m}$ spouted bed using conditions in Case A (reference case) listed in Table 1. 

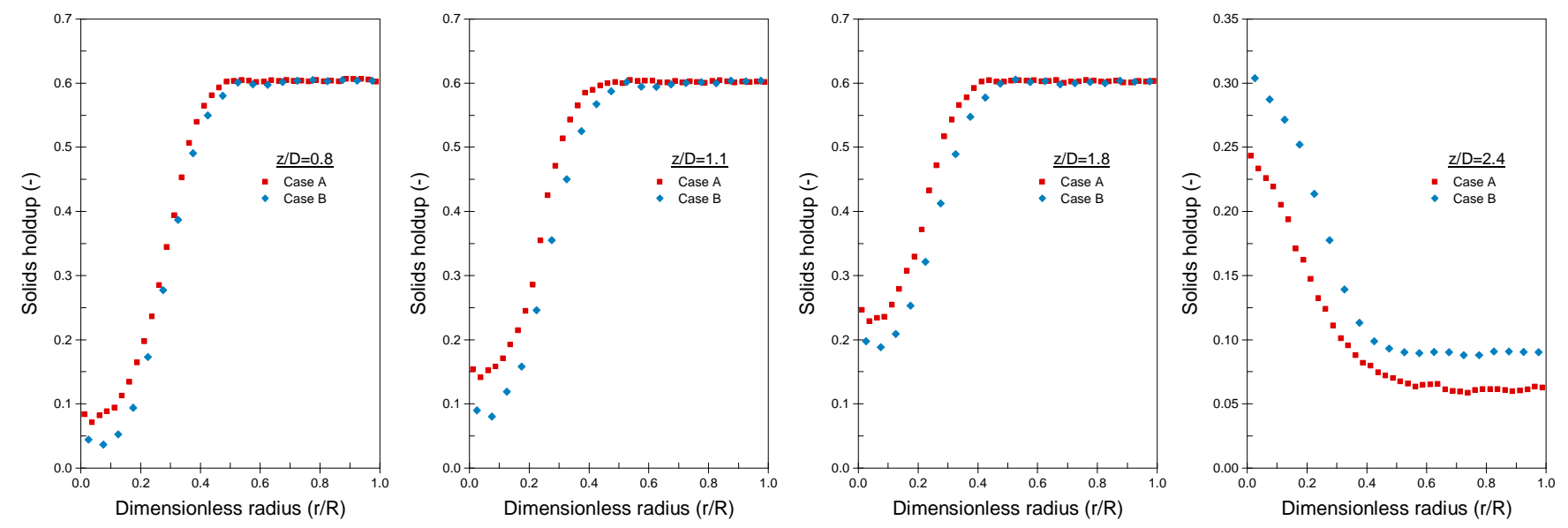

Figure 9. Comparison of radial profiles of solids holdup at z/D levels of 0.8, 1.1, 1.8, and 2.4 for

Case A $(0.152 \mathrm{~m})$ and Case B $(0.076 \mathrm{~m})$ spouted beds. 

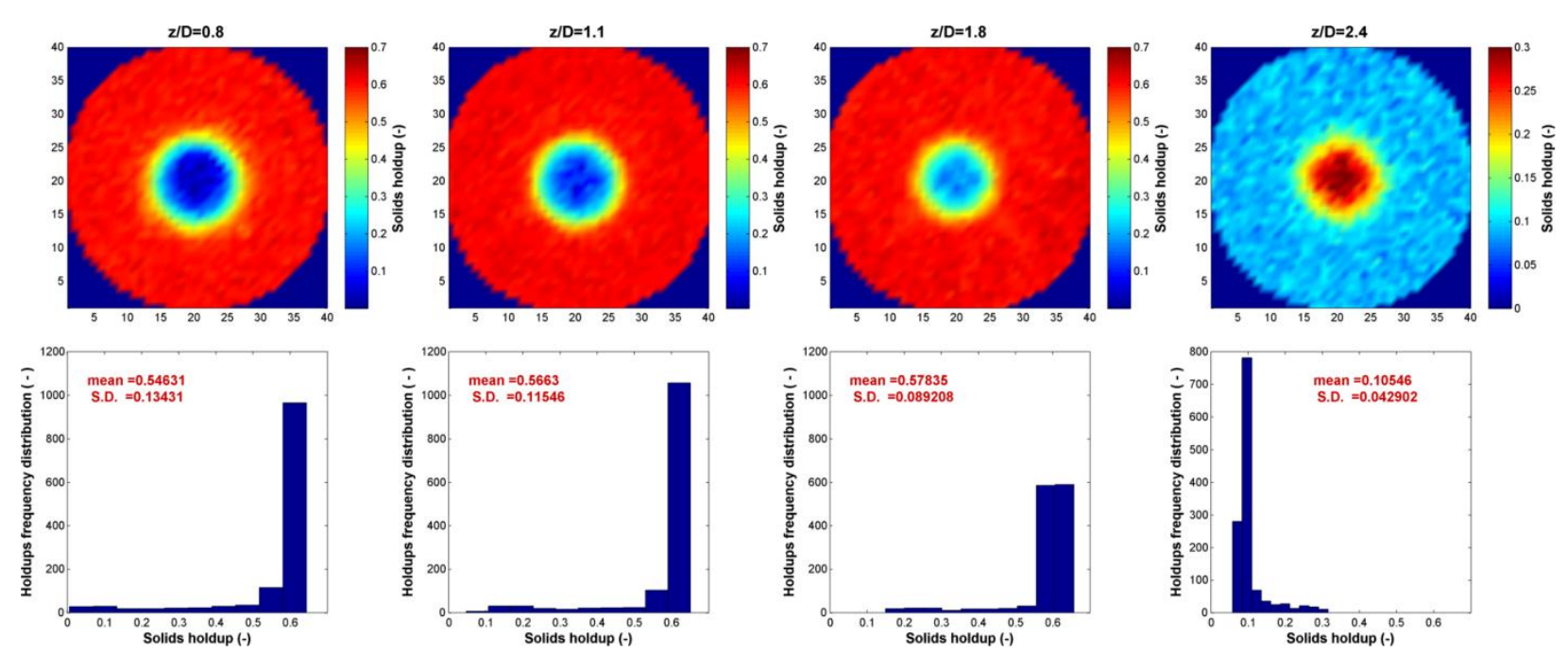

Figure 10. Cross-sectional image and corresponding frequency distribution of solids holdup for Case B along the bed height of the $0.076 \mathrm{~m}$ spouted bed. 

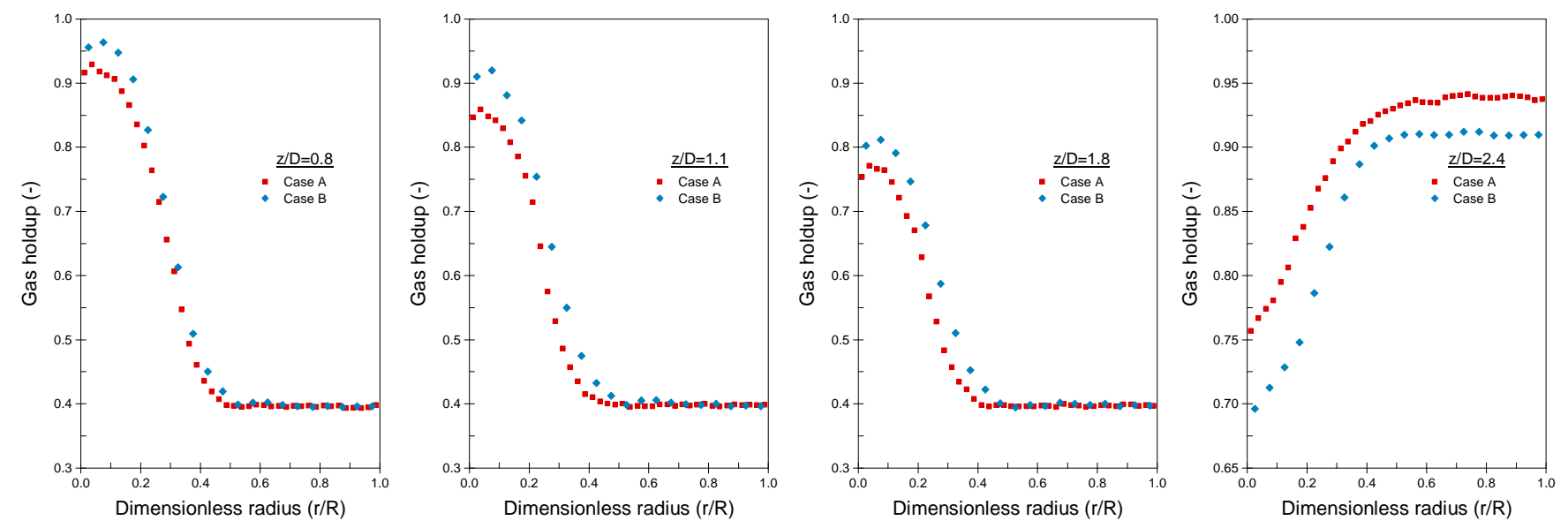

Figure 11. Comparison of radial profiles of gas holdup at z/D levels of $0.8,1.1,1.8$, and 2.4 for Case A $(0.152 \mathrm{~m})$ and Case B $(0.076 \mathrm{~m})$ spouted beds. 

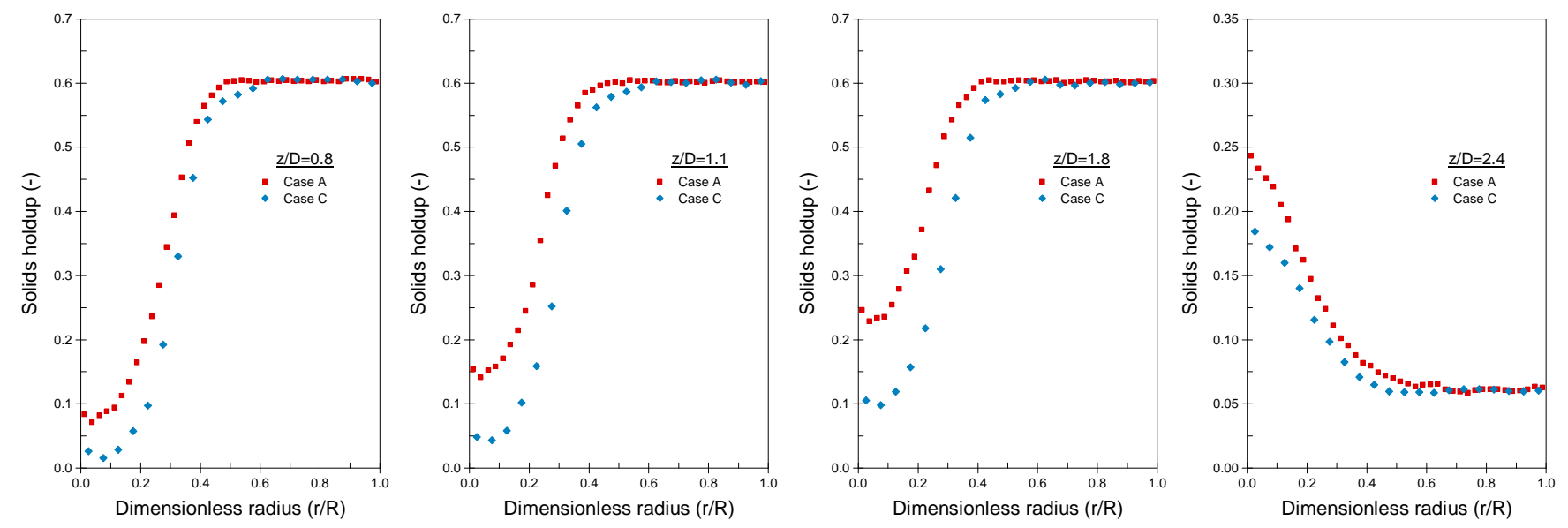

Figure 12. Comparison of radial profiles of solids holdup at z/D levels of $0.8,1.1,1.8$, and 2.4 for

Case A (0.152 m) and Case C (0.076 m) spouted beds. 

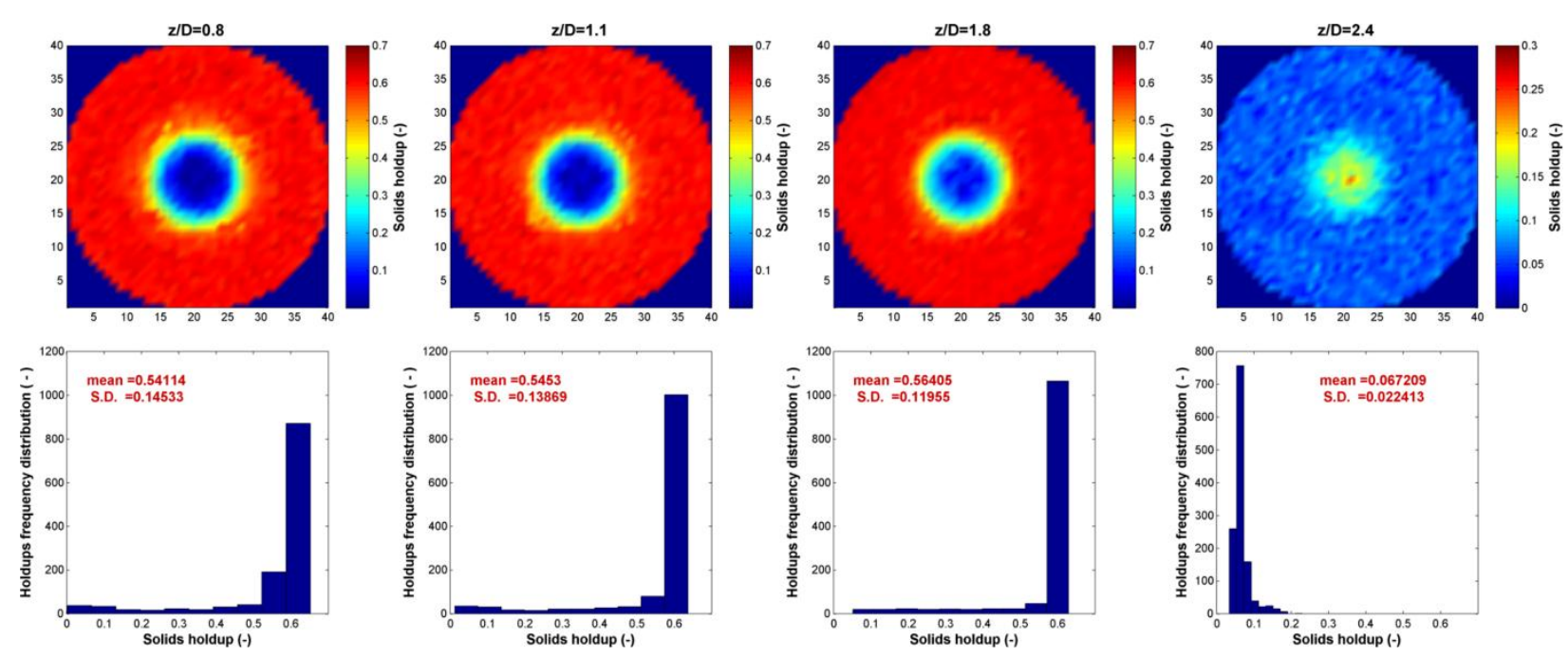

Figure 13. Cross-sectional image and corresponding frequency distribution of solids holdup for Case C along the bed height of the $0.076 \mathrm{~m}$ spouted bed. 

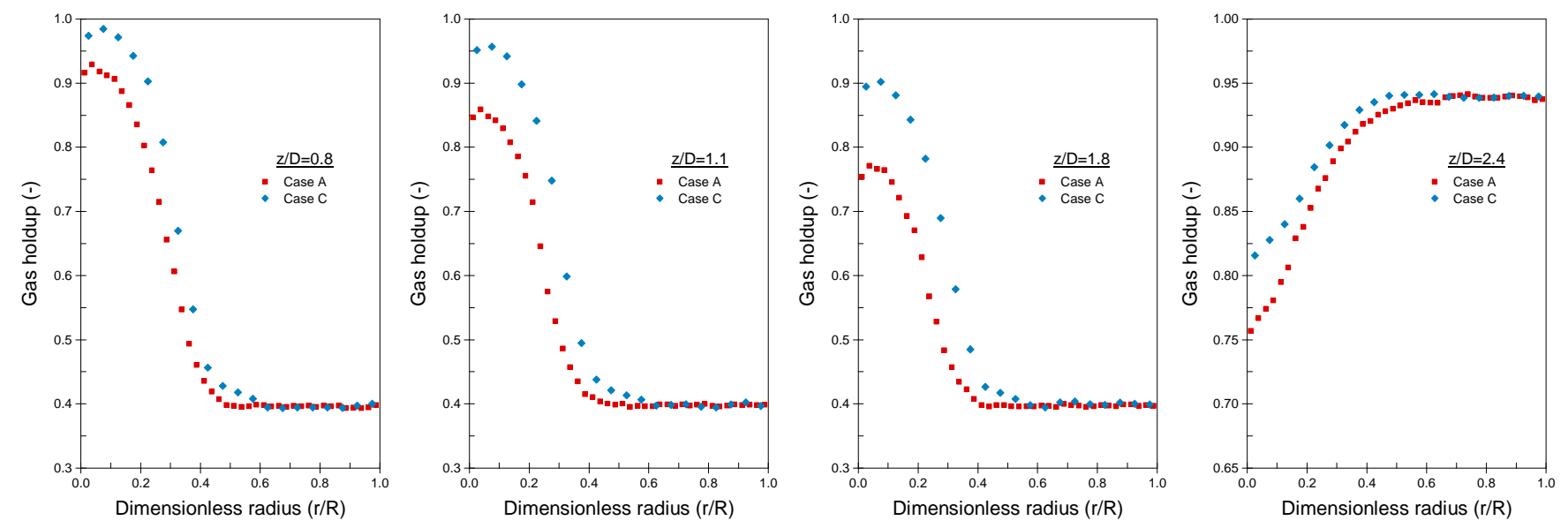

Figure 14. Comparison of radial profiles of gas holdup at z/D levels of 0.8, 1.1, 1.8, and 2.4 for Case A (0.152 m) and Case C (0.076 m) spouted beds. 